\title{
Effects of various salt concentrations on shelf life and quality of Eriobotrya japonica fruit at ambient temperature
}

\author{
Soil Ahmed ${ }^{1}$, Ijaz Husain', Shujaat Ali ${ }^{1}$, Shah Masaud Khan', Kaleem Khan',Affan khan', Asad Ullah Khan*1 \\ ${ }^{1}$ Department of Horticulture Faculty Basic and Applied Sciences, The University of Haripur, Khyber Pakhtunkhwa, \\ *Corresponding Author Email: asadullah3413@gmail.com
}

\begin{abstract}
Eriobotrya japonica (Loquat), a subtropical evergreen tree, is a good source of minerals and phytochemicals; its fruit is disbursed in fresh and preserved forms. At the same time, its kernel is rich in protein and carbohydrates. The study was conducted to determine the effects of several salt concentrations in E. japonica fruits at ambient conditions. Weight-tovolume ratios were prepared for two concentrations of both $\mathrm{KCl}$ and $\mathrm{NaCl}$. Fruit weight, seed weight, and flesh weight were calculated by standard electrical balance. The total number of seeds in the fruit, including the total number of healthy seeds and total no of aborted seeds, was also calculated manually. The result shows that the maximum fruit weight was calculated in fruit treated with $6 \mathrm{~g} \mathrm{NaCl}$ and the minimum fruit weight was calculated in Control. Maximum flesh weight was calculated after 9 days in fruits coated with $6 \mathrm{~g} \mathrm{NaCl}$, and minimum flesh weight was calculated in uncoated fruits. The maximum total antioxidants and total phenolic compounds (TPC) were measured at 6 days of storage. Total phenolic compounds (TPC) activity was calculated after 9 days in uncoated fruits and coated fruits which were minimum in fruits coated with $6 \mathrm{~g} \mathrm{KCl}$. It was concluded that the salts might maintain the fruit quality at ambient temperature and preserve maximum fruit quality for 9 days of storage.
\end{abstract}

Keywords: Eriobotrya japonica, concentrations, salts, fruit quality, ambient temperature

Highlights:

- The study explores the quality and shelf life of the Eriobotrya japonica fruit under salts concentration and storage periods

- The effects of salts were monitored on the weight of three types of seeds.

- Fruit quality shelf life of Eriobotrya japonica at ambient temperature.

\section{Introduction}

Loquat (Eriobotrya japonica Lindl.) is a perpetual tree widely cultivated in the fall and winter season because of its sweet edible fruits (Diwanay et al. 2014). It is highly nectariferous, with a powerful aroma and high honey potential (Yu 1979; Morton 1987; Shaw, 1980; Morton 1987). It has an extensive market value related to its particular nutrients compounds like phenylacetaldehyde, $\beta$-ionone, carotenoids, and hexanoic acid. E. japonica Lindl fruits regularly grow in some regions of the world (McConnell 1988). Its fruits are consumed in fresh or processed form and use as a part of jam, juice, wine, syrup, or as candied fruits (Brondani et al., 2018). Its seeds are used in wine formulation due to their maximum starch contents (20\%), while leaves and fruits are conventionally considered for their medicinal value (Ducos et al.2010; Wee and Hsuan 1992; Chen 1988; Wang 1989; Ichinose 1995). The quality of E. japonica Lindl has an optimum quality, depending on the fully ripe and ripening stages. However, in commercial situations where transport and shelf-life are involved, $E$. japonica Lindl is generally harvested at the eating-ripe stage before fully ripe. In most cultivars, a harvest date is determined by skin color changes described for each cultivar.

China and Japan are the top countries in the cultivation of E. japonica Lindl, whereas, in China, its sale is higher than citrus and banana in the season, followed by lower than Iongan and litchi similar to the sale of apple and pear(Lin 2006).

E. japonica Lindl fruit is very vulnerable to mechanical impairment in harvesting and management. It can quickly develop a browning spot on the fruit surface and pulp (Lin 2006). Storage at low temperatures is effective in extending the postharvest life of the fruit of the Mogi cultivar. Ding et al. (1998) reported that fruit could be stored at 1 or $5^{\circ} \mathrm{C}$ for up to 30 days. However, fruit weight and acidity were progressively lost and, consequently, fruit quality was adversely affected (Hamauzu et al., 1997). Recently, Ding et al. (2002) established that E. japonica Lindl fruit might be stored in the modified atmosphere created by low-density polyethylene bags at $5^{\circ} \mathrm{C}$ for two months. Due to the relatively high respiration rate of 
E. japonica Lindl fruit, low-temperature storage was required to maintain the internal carbon dioxide and oxygen concentration below $5 \mathrm{kPa}$ and $4 \mathrm{kPa}$, respectively.

E. japonica Lindl is famous worldwide due to the mild, subacid, vitamins and minerals, phenolic and carotenoids contents, and sweet taste of its fruit (Xu \&Chenl 2011) and has been shown to inhibit low-density lipoproteins (Koba et al. 2007). The bioactive components of E. japonica Lindl show remarkably high scavenging activity against chemically generated radicals. These bio compounds are flavonoids (founds in peels only), triterpene acids, and carotenoids (Liang et al. 2010; Godoy et al. 1995), making them effective in inhibiting the oxidation of human low-density lipoproteins (Barreto et al. 2009).

The current study investigates the effects of salts concentrations on the quality of E. japonica Lindl fruit at ambient temperature. Furthermore, phytochemicals and physiochemical changes are also discussed in the relevant section of the article.

\section{Materials and Method}

\subsection{Collection of fruits and experiment site}

The fresh and matured E. japonica Lindl fruits were obtained from the Haripur region farm and brought to Horticulture lab $\mathrm{UOH}$ after collection. The grading and washing were done on these fruits, and after washing, the fruit was drying and dipped in salts dipping.

\subsection{Treatments applications}

Following treatment of salt were made per $300 \mathrm{~mL}$ of water to apply on fruits viz To Control (untreated fruits), $\mathrm{T} 1: 6 \mathrm{~g} \mathrm{KCl}$ $1300 \mathrm{ml}$ water, T2:12 $\mathrm{g} \mathrm{KCl} / 300 \mathrm{ml}$ Water, T3: $3 \mathrm{~g} \mathrm{NaCl} / 300 \mathrm{ml}$ Water and T4: $6 \mathrm{gNaCl} / 300 \mathrm{ml}$ Water

\subsection{Treatment methods and storage days}

The fruits were individually dipped in a prepared solution of both salts for 15 minutes. Some fruits were stored for 3,6,9 days of storage and then transferred for their analyses as fresh and stored fruit.

\subsection{Physiochemical parameters of E. japonica Lindl fruits}

Physicochemical parameters of fruits were recorded, including $\mathrm{pH}$, measured by standard $\mathrm{pH}$ meter while fruit, flesh, healthy, and aborted seeds weight of fruits recorded by standard electrical balance.

2.5 Total antioxidant activity by 2, 2-diphenyl-1-picrylhydrazyl stable radicals.

Total antioxidants activities of the fruit juice were assessed by measuring their scavenging

abilities to 2, 2-diphenyl-1-picrylhydrazyl stable radicals. The absorbance was read against a

blank at $517 \mathrm{~nm}$ using a microplate ELISA reader (BioTek, USA). Inhibition of free radical determined by

The following formula calculated DPPH in percent (\%):

$$
\text { I } \%=(\text { A blank }- \text { A sample /Ablank }) \times 100
$$

where A blank is the absorbance of the control reaction mixture excluding the fruit sample, and A sample is the absorbance of the test compounds. $\mathrm{IC}_{50}$ values, which represented the concentration of fruit extracts that caused $50 \%$ neutralization of DPPH radicals, were calculated from the plot of inhibition percentage against concentrations.

\subsection{Folin-Ciocalteu for total phenolic compounds}

Total phenolic contents (TPC) were calculated by using the Folin-Ciocalteu reagent method. The FC-reagent (10 mL) was dissolved in distilled water to make the solution $100 \mathrm{~mL}$. In each sample $(100 \mathrm{~mL})$, FC-reagent $(200 \mu \mathrm{L})$ was added and vortex thoroughly. The $700 \mathrm{mM} \mathrm{Na} 2 \mathrm{CO}_{3}$

$(800 \mu \mathrm{L})$ was added into each sample and incubated at room temperature for $2 \mathrm{~h}$. Sample $(200$

$\mu \mathrm{L}$ ) was transferred to a transparent 96-well plate, and the absorbance of each well was measured at $765 \mathrm{~nm}$. The amount of TPC was calculated using a calibration curve for Gallic acid. The results were expressed as Gallic acid equivalent.

\section{Results and Discussion}

\subsection{Effect of different salt concentrations and storage days on Fruit weight of E. japonica Lindl fruit}

The effect of different concentrations of $\mathrm{KCl}$ and $\mathrm{NaCl}$ on the weight of fruits presented in Fig. 1. Fruits treated with $6 \mathrm{~g}$ $\mathrm{NaCl}$ showed maximum weight as compared to untreated fruits. The maximum fruit weight was reported on the third day of storage due to upheld the moisture contents of the fruit, while in 6 and 9 days of stored fruit, the minor loss of fruits has been seen due to changes in the moisture contents and water contents in fruits. The other days of fruits showed a slight variation of fruit weights while fruit weight was higher and referred to as the fruit quality. The lower loss of fruit weight was observed due to salts coverage in this study. 


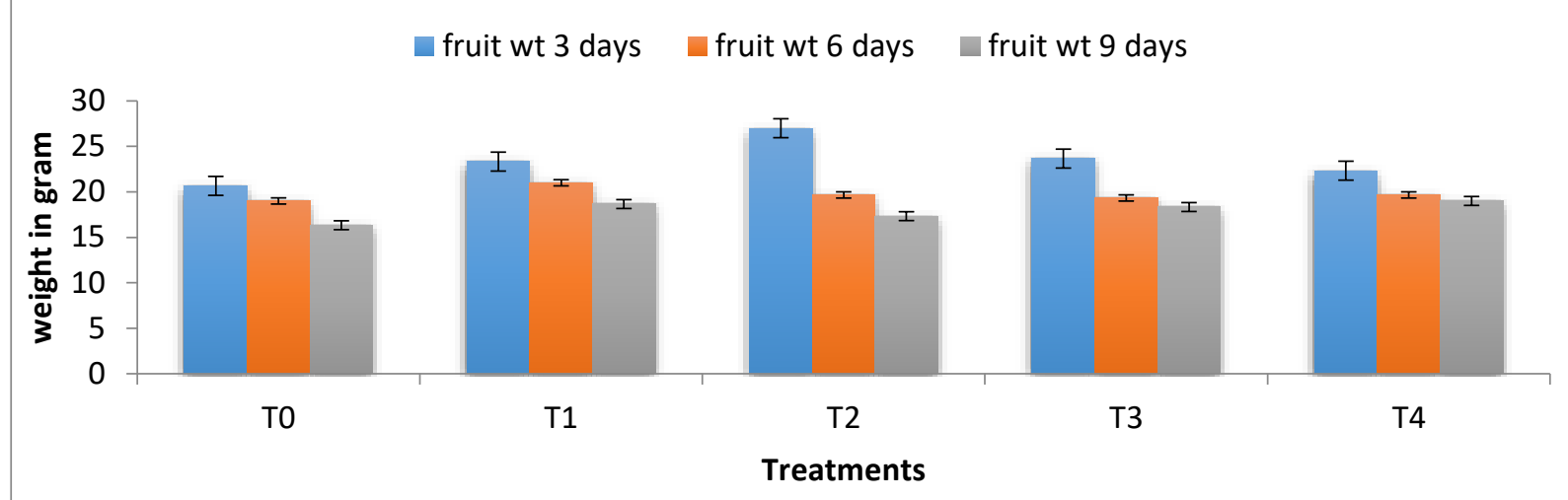

Fig1. Fruit weight of E. japonica Lindl affected by different concentration of treatment of $\mathrm{KCl}$ and $\mathrm{NaCl}$

\section{2 Effect of different salt concentrations on number of healthy and Aborted seeds of E. japonica Lindl fruits and storage periods}

The effects of different concentrations of $\mathrm{KCl}$ and $\mathrm{NaCl}$ treatments on a number of seeds of $E$. japonica Lindl are presented in Fig. 2. No significant differences in healthy seeds were found among the treatments and storage days of fruits ( Fig. 2), followed by no substantial variances in the number of seeds of E. japonica Lindl fruits (Fig.3). In contrast, some lower healthy seeds were observed in 9 days of storage (Fig 4). The concepts of the seed changes have significant enhancements due to its early development of fruit structure. Later, the quality changes have been maintained, and no morphological and structural changes of fruits were reported (Diwanay et al., 2014).

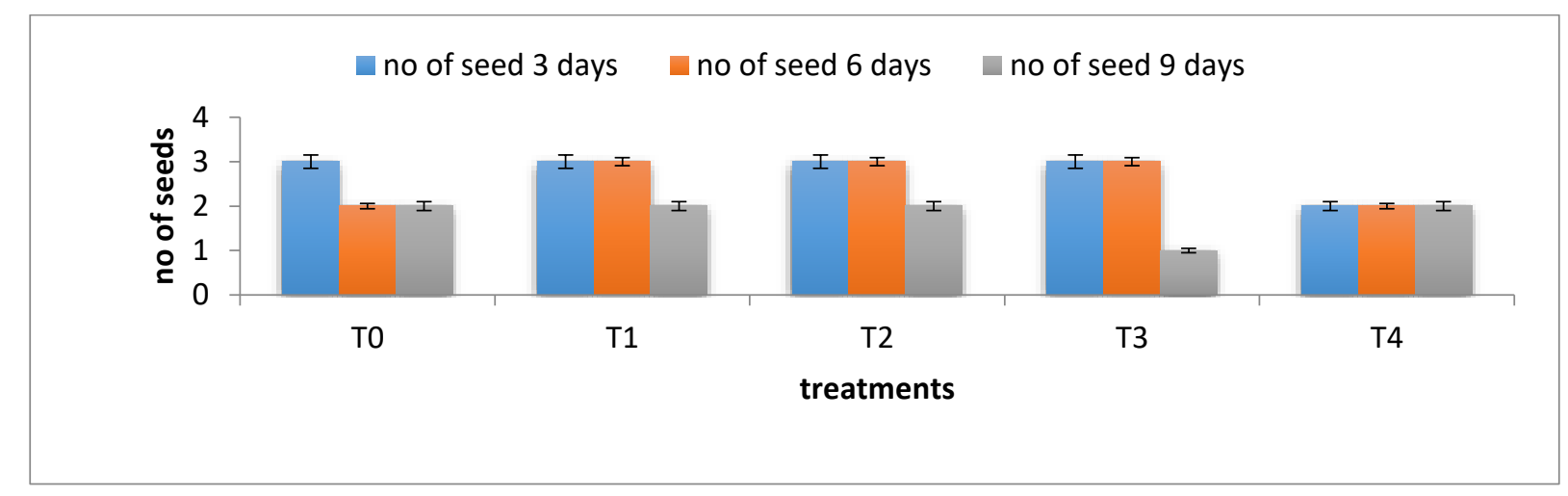

Fig. 2. No of seeds of E. japonica Lindl affected by different concentration of treatment of $\mathrm{KCl}$ and $\mathrm{NaCl}$

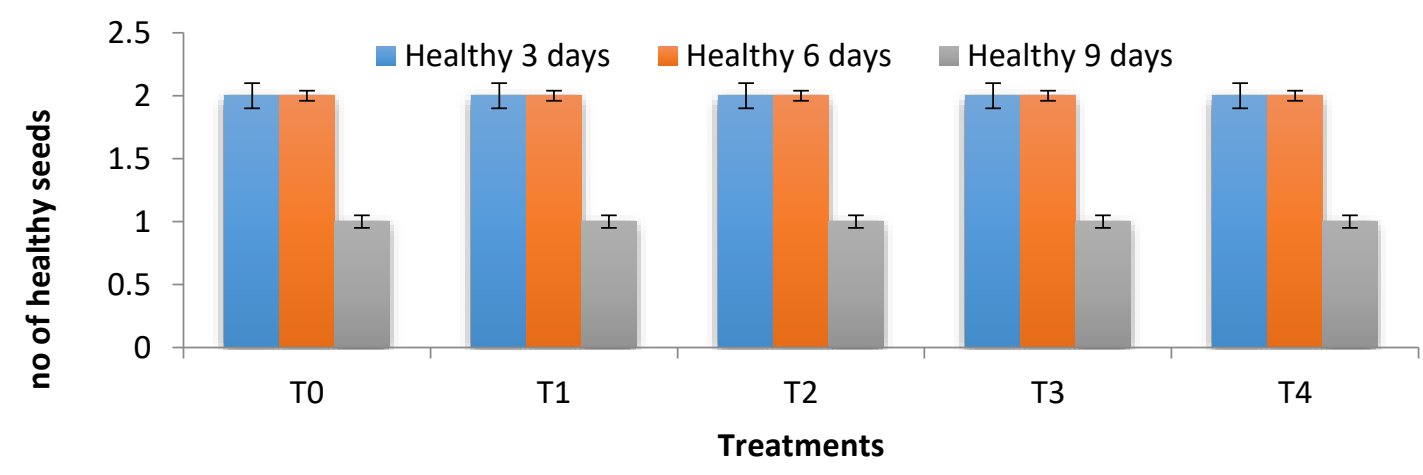

Fig. 3. No of healthy seeds of E. japonica Lindl affected by different concentration of treatment of $\mathrm{KCl}$ and $\mathrm{NaCl}$ 


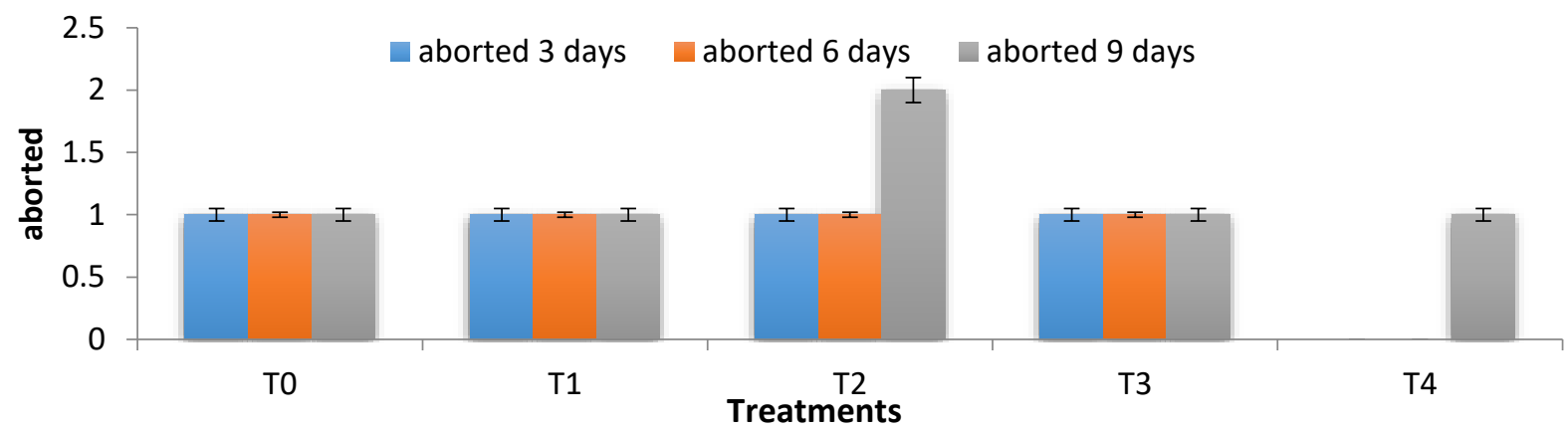

Fig. 4. No of aborted seeds of E. japonica Lindl affected by different concentration of treatment of $\mathrm{KCl}$ and $\mathrm{NaCl}$

\subsection{Effect of different salt concentrations on Seed, Flesh weight}

The effects of storage period and treatments of salts of $\mathrm{NaCl}$ and $\mathrm{KCl}$ on the weight of seeds of E. japonica Lindl fruits are presented in Fig.5. The higher weight of seed was reported in untreated fruit as compared to treated fruits. The $3 \mathrm{~g}$ $\mathrm{NaCl} / 300 \mathrm{ml}$ Water showed less seed weight $(1.33 \mathrm{~g})$. Significant differences were found in storage days and treatments on flesh weight (Fig 6). The flesh weight of E. japonica Lindl was higher in treated fruits as compared to untreated fruits. Fruits treated with $6 \mathrm{~g} \mathrm{NaCl}$ showed maximum flesh weight compared to untreated fruits. The salts improve the quality of the flesh and improve the enzymatic activities, and lower water losses in the internal structure of fruits which was similar to the earlier reported work of Baskaran et al.(2006).

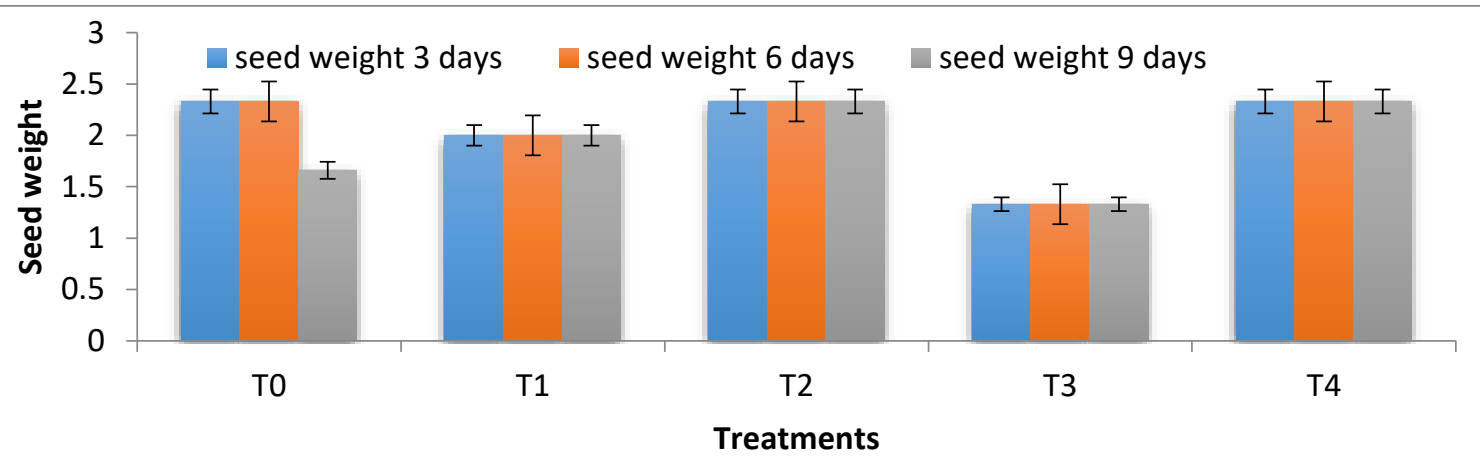

Fig.5. Seed weight of E. japonica Lindl affected by different concentration of treatment of $\mathrm{KCl}$ and $\mathrm{NaCl}$

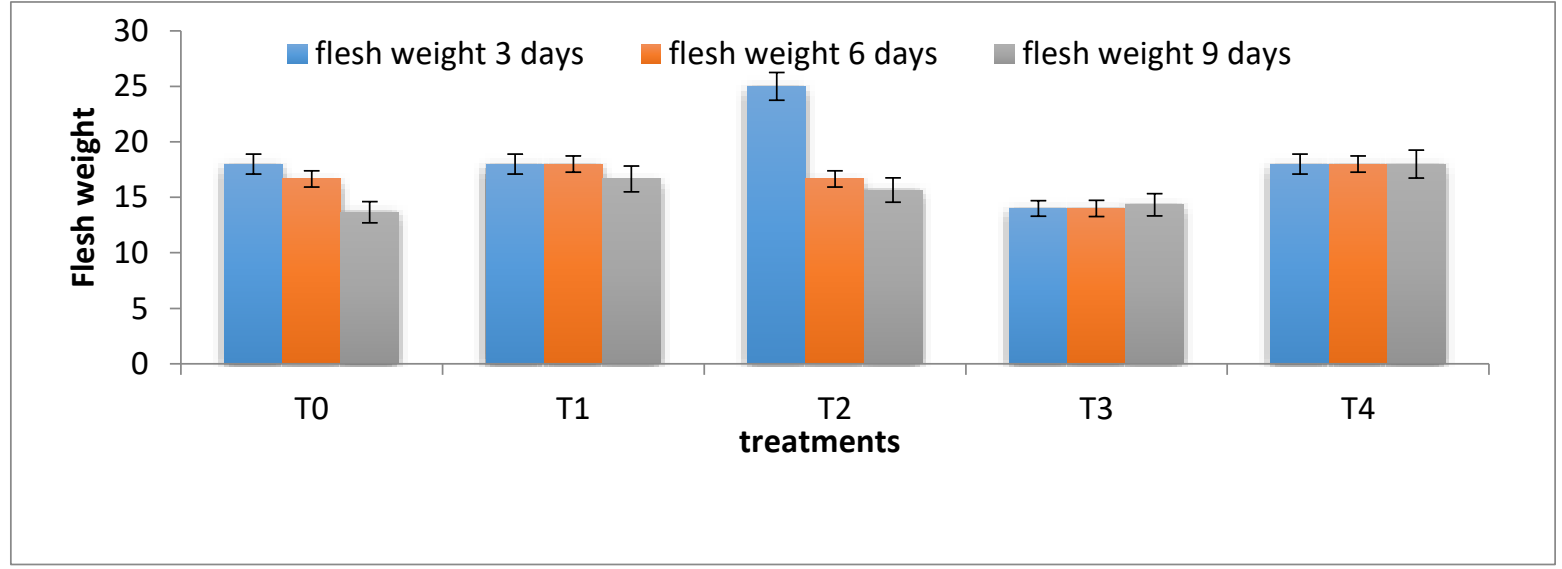


Fig 6. flesh weight of E. japonica Lindl affected by different concentration of treatment of $\mathrm{KCl}$ and $\mathrm{NaCl}$

\subsection{Phenolic compounds, total Antioxidant, and pH of fruits under treatment}

Substantial alterations were observed in the treatments and the storage days of E. japonica Lindl (Fig 7) regarding TPC and TA, where a relationship was observed in total phenolic and antioxidants with the storage period. The effects of salts concentration showed significant improvement of TPC on the $6^{\text {th }}$ day of storage. At the same time, it was lower from the initial to $3^{\text {rd }}$ day. Fruits treated with $3 \mathrm{~g} \mathrm{NaCl}$ showed maximum TPC as compared to untreated fruits. Fruits treated with $6 \mathrm{~g}$ $\mathrm{NaCl}$ showed maximum TA compared to fruits that were left untreated. The improved TPC during the storage period is related to the activation of several enzymes, as Baranek et al. (2006) reported in their study. The variations of antioxidants activity against the storage days and treatments are represented in Fig.8. The higher values of antioxidants were measured at six days of storage period while a little variation of TA was observed in 9 days of storage. The higher activity of TA was observed in $6 \mathrm{~g}$ of $\mathrm{NaCl}$ treated fruit, while lower activity was found in untreated. The antioxidants were increased or decreed from the ripening of fruits. Storage conditions for control fruits reduced the antioxidants activity in untreated fruit, a similar investigation reported by Baranek et al. (2006) in peach fruit. The significant differences in $\mathrm{pH}$ were found in storage days and treatments of E. japonica Lindl fruits shown in Fig 9. The maximum $\mathrm{pH}$ values were found in treated fruits of $6 \mathrm{~g}$ of $\mathrm{NaCl}$, while lower values were found in untreated fruit.

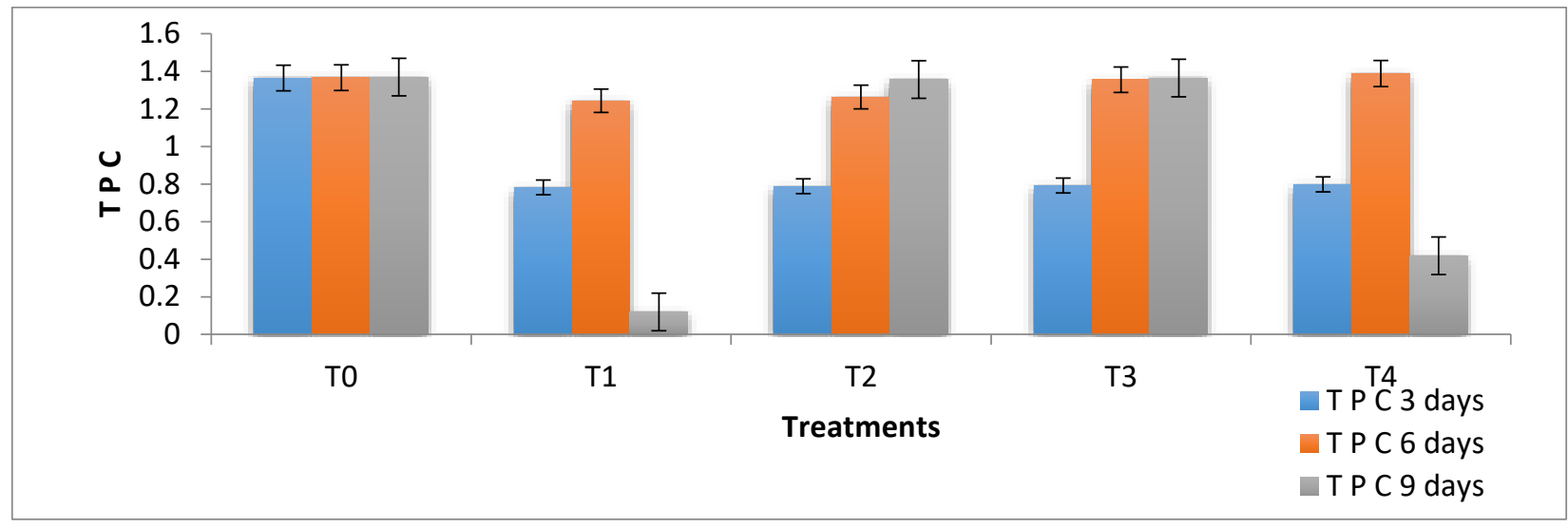

Fig 7. TPC of E. japonica Lindl affected by different concentration of treatment of $\mathrm{KCl}$ and $\mathrm{NaCl}$

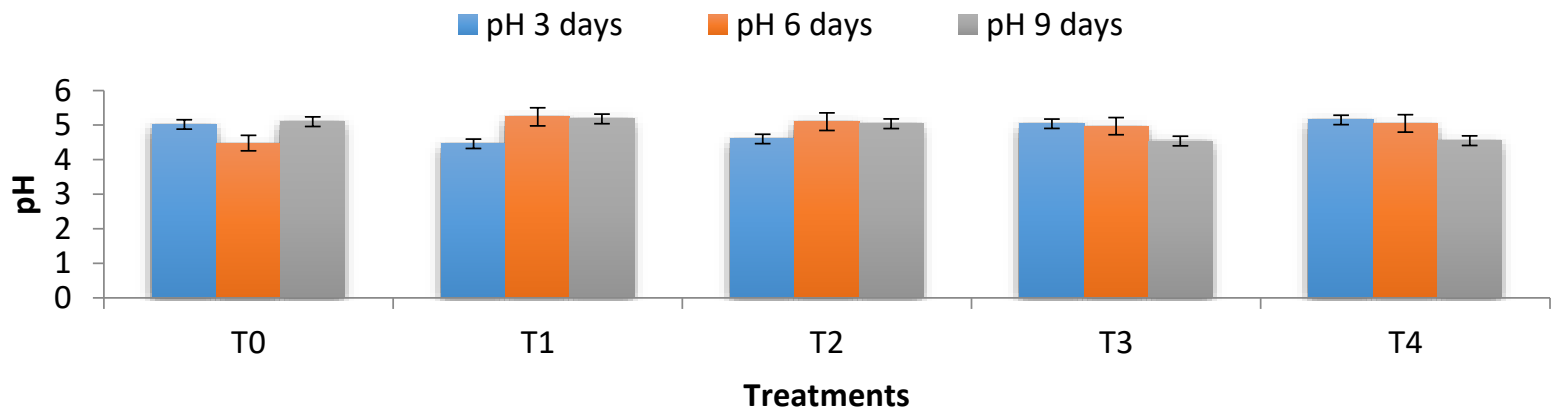

Fig 9. $\mathrm{pH}$ of E. japonica Lindl affected by different concentration of treatment of $\mathrm{KCl}$ and $\mathrm{NaCl}$ 


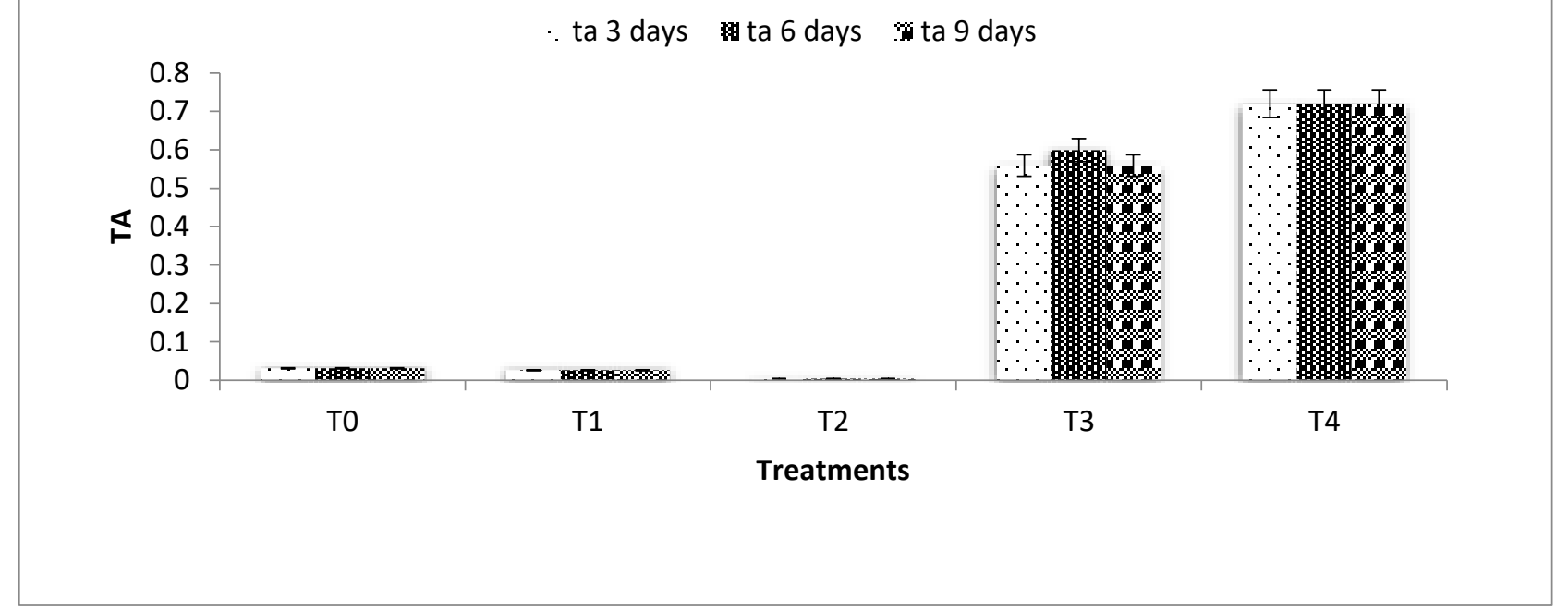

Fig 8. TA of E. japonica Lindl affected by different concentration of treatment of $\mathrm{KCl}$ and $\mathrm{NaCl}$

\section{Conclusion}

it was concluded that the average life of the E. japonica Lindl fruits could be enhanced by the treatment of salts from 2 days to six days, while the salts' treatments were significantly improved the fruit quality shelf life at storage periods of 6 and 9 days. The effect of salt concentration did not alter the fruit quality and found adequate to maintain nutritional contents; both salts of $\mathrm{NaCl}$ and $\mathrm{KCl}$. The treatments had a beneficial effect on reducing postharvest losses of E. japonica Lindl fruit. However, treatments with $\mathrm{KCl}$ proved to be the best among all treatments and can be used commercially to reduce postharvest losses of E. japonica Lindl fruit. It is recommended that the farmers use these salts to preserve E. japonica Lindl through an essay and friendly method.

\section{Acknowledgments.}

The authors highly appreciate the Department of Horticulture, The University of Haripur, to complete this project

\section{Conflict of interest}

It is declared that there is no conflict of interest among the authors.

\section{References}

Aguayo E, Allende A, Artés F. (2003). Keeping quality and safety of minimally fresh processed melon. Eur. Food Res. Technol. 216, 494-499

Artés F, Gómez P, Aguayo E, Escalona V, Artés-Hernández F. 2009. Sustainable sanitation techniques for keeping quality and safety of fresh-cut. Postharvest Biol. Technol. 51, 287-296.

BadenesML,Martınez-Calvo J, Llacer G (2000).Analysis of a germ plasm collection of loquat (Eriobotrya japonica Lindl.) Euphytica, 114:187-194.

Balandrin MJ, Klocke JA (1998). Medicinal, aromatic and industrial materials from plants. In: Bajaj YPJ, editor. Biotechnology in agriculture and forestry. Medicinal and aromatic plant, 4:1-36.

Baranek M, Raddova J, Pidra M (2006). Comparative analysis of genetic diversity in Prunus L. as revealed by RAPD and SSR markers. SciHort, 108:253-259.

Barreto GPM, Benassi MT and Mercadante AZ, Bioactive compounds from several tropical fruits and correlation by multi variate analysis to free radical scavenger activity. J BrazChem Soc20:1856-1861 (2009).

Barrett-Connor E (1998).Hormone replacement therapy, heart disease, and other considerations. Ann Rev Pub Health, 19:55-72. 
Baskaran P, Jayabalan N (2005). An efficient micropropagation system for eclipta alba- A valuable medicinal herb, in vitro cellular and developmental biology- Plant, 41:532-539.

Baskaran SA, Upadhyay A, Kollanoor-Johny A, Upadhyaya I, Mooyottu S, Amalaradjou MAR, Schreiber D, Venkitanarayanan K. 2013. Efficacy of plant-derived antimicrobials as antimicrobial wash treatments for reducing enterohemorrhagic Escherichia coli O157:H7 on apples. J. Food Sci. 78, M1399-M1404.

Bassil NV, Botta R, Mehlenbacher SA (2005). Microsatellite markers in hazelnut: isolation, characterization, and crossspecies amplification. J AmerSocHortSci, 130:543-549.

Benmoussa M, Mukopadhyaya S, Desjardins Y (1996) Optimization of tissue culture and shoot multiplication of Asparagus densiflorus. Plant Cell Tiss Org Cult, 47:91-94.

Brondani C, Rangel PH, Borba TC, Brondani RP (2018). Transferability ofmicrosatellite and sequence tagged site markers in Oryza species. Hereditas, 138:187-192.

Cantín CM, Minasa IS, Goulas V, Jiménez M, Manganaris GA, Michailides TJ, Crisosto CH. 2012. Sulfur dioxide fumigation alone or in combination with $\mathrm{CO} 2$-enriched atmosphere extends the market life of highbush blueberry fruit. Postharvest Biol. Technol. 67, 84-91.

Carrasco G, Urrestarazu M. 2010. Green chemistry in protected horticulture: the use of peroxyacetic acid as a sustainable strategy. Int. J. Mol. Sci. 11, 1999-2009.

Cengiz MF, Certel M. 2013. Effects of chlorine, hydrogen peroxide, and ozone on the reduction of mancozeb residues on tomatoes.Turk. J. Agric. For. 38, 1-6

Chen JT, Chang WC (2000). Efficient plant regeneration through somatic embryogenesis from callus cultures of Oncidium(Orchidaceae). Plant Science, 160: 87-93.

Chengalrayan K, Hazra S, Gallo-Meagher M (2001). Histological analysis of somatic embryogenesis and organogenesis induced from mature zygotic embryo-derived leaflets of peanut (ArachishypogaeaL.)Plant Science, 161:415-421.

Chevreau E, Leuliette S, GalletM (1997). Inheritance and linkage if isozymeloci in pear (Pyruscommunis L.).Theor. Appl. Genet, 94:498-506.

Choumane W, Winter P, Weigand F, Kahl G (2004).Conservation of microsatellite flanking sequences in different taxa of Leguminosae. Euphytica, 138:239-245.

Chozin M (2007).Characterization of sorghum accessions and choice of parents for hybridization. Journal AktaAgrosiaEdisiKhusus, 227-232.

Chuech FS, Chen CC, Sagare AP, Tsay HS (2001).Quantitative determination of secoiridoid glucosides in in vitro propagated plants of Gentianadavidii var. formosana by high performance liquid chromatography Planta Medica, 67:70-73.

Ding, C.K., Chachin, K., Hamauzu, Y., Ueda, Y. and Imahoti, C.Y. (1998). Effects of storage temperatures on physiology and quality of loquat fruit. Postharvest Biol. and Technol., 14: 309315.

Ding, C.K., Chachin, K., Ueda, Y., Imahoti, C.Y. and Wang, C.Y (2002). Modified atmosphere packaging maintains postharvest quality of loquat fruit. Postharvest Biol. and Technol., 24: 349348.

Diwanay S, Chitre D, Patwardhan B (2014). Immunoprotection by botanical drugs in cancer chemotherapy. J Ethnopharmacol, 90:49-55.

Ducos JP, Terrier B, Courtois D (2010).Disposable bioreactors for plant micropropagation and mass plant cell culture.AdvBiochemEng/Biotech, 115:89-115.

Duraipandiyan V, Ayyanar M, Ignacimuthu S (2006). Antimicrobial activity of some ethnomedicinal plants used by Paliyar tribe from Tamil Nadu, India. BMC Complement Altern Med, 6:35-50. 
Elameen A, Larsen A, S, Klemsdal SS, Fjellheim S, Sundheim L, Msolla S, Masumba E, Rognli OA (2011). Phenotypic diversity of plant morphological and root descriptor traits within a sweet potato, Ipomoea batatas (L.) Lam., germplasm collection from Tanzania Genet Resour Crop Evol, 58:397-407.

Koba, K., Matsuoka, A., Osada, K., \& Huang, Y. S. (2007). Effect of loquat (Eriobotrya japonica) extracts on LDL oxidation. Food Chemistry, 104(1), 308-316.

Liang, G. L., Wang, W. X., Li, X. L., Guo, Q. G., Xiang, S. Q., \& He, Q. (2010, May). Selection of large-fruited triploid plants of loquat. In III International Symposium on Loquat 887 (pp. 95-100).

Lin, S. Q. (2006, April). World loquat production and research with special reference to China. In II International Symposium on Loquat 750 (pp. 37-44).

$\mathrm{Xu}, \mathrm{H}$. X., \& Chen, J. W. (2011). Commercial quality, major bioactive compound content and antioxidant capacity of 12 cultivars of loquat (Eriobotrya japonica Lindl.) fruits. Journal of the Science of Food and Agriculture, 91(6), 1057-1063. 